\title{
DISPOSITIVOS CONVENTUALES Y RESOCIALIZACIÓN RELIGIOSA: ETNOGRAFÍA DEL ARTE DE HACERSE FRAILE ${ }^{1}$
}

\author{
Alejandro Rodriguez López²
}

\begin{abstract}
Resumen: A partir de una inserción etnográfica realizada en un convento franciscano de Chiapas (México), el objetivo de este artículo es analizar el proceso de resocialización de sujetos que emprenden el camino formativo en esta orden religiosa. El trabajo pone atención en los marcos cotidianos de la iniciación conventual que tiene lugar en la etapa de noviciado; las formas disciplinares de construcción de la experiencia religiosa; la indecencia en el cuerpo; y las narrativas de justificación y consagración institucional. Al mismo tiempo, proponemos una discusión teórica que articule institución (religión) y religiosidad en el ámbito de las órdenes religiosas católicas para la observación de prácticas religiosas históricamente situadas. Finalmente, y como último aspecto del vínculo entre institución, religiosidad y subjetividad, se propone la reconstrucción de las condiciones generales de la vida franciscana en México después del Vaticano II, como aspecto central para comprender las formas contemporáneas de optar y vivir la vocación religiosa franciscana.
\end{abstract}

Palabras clave: Etnografía; Vida Religiosa; Iniciación Conventual; Franciscanos; Chiapas.

CONVENTUAL DEVICES AND RELIGIOUS RESOCIALIZATION: ETHNOGRAPHY OF THE ART OF BECOMING A FRIAR

\begin{abstract}
From an ethnographic insertion carried out in a Franciscan convent in Chiapas (Mexico), the objective of this article is to analyze the process of resocialization of subjects who undertake the formative path in this religious order. The work pays attention to the daily settings of the conventual initiation
\end{abstract}

1 Como citar: RODRÍGUEZ, Alejandro. Dispositivos conventuales y resocialización religiosa: etnografía del arte de hacerse fraile. Debates do NER, Porto Alegre, v. 1, n. 37 , p. 169-200, 2020.

2 Doutorando em Antropologia pela Universidad Nacional Autónoma de México, México. E-mail: alrolopez86@hotmail.com. 
that takes place in the novitiate stage; the disciplinary forms of construction of the religious experience; indecency in the body; and the narratives of justification and institutional consecration. At the same time, we propose a theoretical discussion that articulates institution (religion) and religiosity in the field of Catholic religious orders for the observation of historically situated religious practices. Finally, and as the last aspect of the link between institution, religiosity and subjectivity, the reconstruction of the general conditions of Franciscan life in Mexico after Vatican II is proposed, as a central aspect to understand contemporary ways of choosing and living the Franciscan religious vocation.

Keywords: Ethnography; Religious Life; Conventual Initiation; Franciscans; Chiapas.

\section{INTRODUCCIÓN}

Sociológicamente hablando, las congregaciones y órdenes religiosas católicas son organizaciones corporativas, descentralizadas y multiterritoriales (Masferrer, 2004; Rubial, 2013). Establecen fuertes vínculos de agregación entre sus integrantes, superponen los propósitos colectivos a los personales, y subordinan lo individual bajo el modelo idealizado del ser institucional, fijado en la imagen del fundador. No obstante, y contrario a las pretensiones ideológicas de separación del mundo, la vida religiosa consagrada no está exenta de determinaciones histórico-sociales para construir su ser y quehacer institucional. A pesar de la indudable presencia de los religiosos en la configuración histórica de las religiosidades; el interés académico en México sobre esta forma de vida está centrado en su participación dentro de la vida social y 
religiosa de la Nueva España, ${ }^{3}$ y son escasas las reflexiones para los contextos del México independiente y contemporáneo. Esta condición en las ciencias sociales mexicanas, según García y Rosas (2016), ha ocasionado un vacío importante en la historiografía y socioantropología de las congregaciones religiosas en el siglo XX, dejando sin atender los reacomodos recientes de las órdenes históricamente más importantes, o de las varias congregaciones fundadas en la primera mitad del siglo XX. ${ }^{4}$

Los trabajos existentes sobre religiosos o sacerdotes católicos, valiosos para abrir agenda, más que reflejar acciones de reflexión conjunta, son esfuerzos personales, aislados y, penosamente, con poco diálogo entre ellos. Aunado a esto, como menciona Padilla $(2008,2015)$, quienes toman como objeto de sus preocupaciones al clero católico, enfatizan la relación entre política y religión, ${ }^{5}$ y en muchos casos se basan fundamentalmente en el punto de vista de la alta jerarquía del catolicismo, generalmente perteneciente al clero secular. Esto oculta no sólo al clero regular sino a las diversas posturas, a veces encontradas, que hacen parte de eso que por comodidad se ha llamado

3 Para una visión panorámica y temáticamente guiada de la basta bibliografía sobre las órdenes religiosas activas en los procesos de evangelización y construcción de la sociedad novohispana, véase la valiosa síntesis bibliográfica de García y Rubial (2018), en la que dedican varios apartados a los dominicos, franciscanos, jesuitas, agustinos, mercedarios y carmelitas descalzos. En términos generales, estas investigaciones explican la proyección política y cultural de los religiosos hacia fuera de los claustros; sin estudiar la vida cotidiana intramuros.

4 Fuera de México existen investigaciones sobre vida conventual y monástica contemporáneas que ofrecen enfoques novedosos para atender esta forma de vida, y que para este escrito sirven de trasfondo analítico que anima a hacer de la vida en un claustro, un objeto de indagación social (Ludueña, 2003; Sbardella, 2013; Jonveaux, Palmisano y Pace, 2014; Hervieu-Léger, 2017; Jewdokimow, 2018). Por otro lado, en México son los conventos femeninos más que los masculinos, los que han recibido mayor atención (Manzano-Mugía, 1995; Lester, 2003; Patiño, 2017).

5 En cuanto a los religiosos situados tanto en Chiapas como en América Latina, véanse en esta misma lógica analítica los trabajos de Robledo (2016), Crispín (2010), Tahar (2007) y Löwy (1999). 
“jerarquía católica”. En otras palabras, y siguiendo la distinción clásica hecha por Simmel (2013), la mirada sobre el clero y los religiosos consagrados ha estado centrada en la organización institucional de la religión establecida; más que en la religiosidad. En este sentido, ¿basta un análisis sociológico de la organización institucional de la religión católica, para comprender las posturas políticas y sociales de los religiosos consagrados en los diversos procesos que se han generado en el país?; ¡es posible dar cuenta del sujeto consagrado, a partir de su mera caracterización del lugar que ocupa dentro del organigrama institucional, y desde ahí explicar el compromiso a los proyectos congregacionales?; jestará faltando en el análisis incluir la religiosidad construida al interior de las órdenes católicas, para tener una visión más profunda de este complejo agregado eclesial y las formas subjetivas de construir las narrativas vocacionales?

El objetivo de este artículo, entonces, es dar cuenta del proceso de resocialización que tiene lugar en el noviciado franciscano de la provincia San Felipe de Jesús, ${ }^{6}$ para hacer visible el lugar de la iniciación conventual en la construcción subjetiva de la adhesión institucional. Asimismo, reconstruyo las condiciones generales del franciscanismo en México después del Vaticano II, y su concreción en la fundación de una provincia en el sureste mexicano. Esto debido a que acercarse al micro mundo de un convento no exenta de dar algunos apuntes de los procesos sociales que están movilizando tanto el contexto actual del franciscanismo mexicano como las biografías de los sujetos; demostrando así las formas contemporáneas de optar y vivir la vocación religiosa franciscana. La presentación de este trabajo está dividida en tres momentos importantes. El primero es una propuesta teórica para vincular el análisis sociológico del catolicismo con una preocupación cultural

6 Las provincias son demarcaciones geográficas-administrativas que organizan las diversas casas de religiosos de una orden católica. Cada provincia goza de cierta autonomía para la toma de decisiones que estructuran su formación y pastoral, pero dependen, al mismo tiempo, de un órgano superior (curia general) que aglutina a todas las provincias para promover la fidelidad al carisma congregacional.

Debates do NER, Porto Alegre, ano 20, N. 37, P. I69-200, JAN./JUl. 2020 
de la religiosidad en los ámbitos de la vida consagrada católica (con énfasis en la subjetividad y la experiencia corporizada). El segundo momento es el inicio del caso de estudio por medio del análisis del proceso de fundación de la provincia San Felipe de Jesús, y de cómo esto forma parte de las nuevas características de la política de expansión de las congregaciones religiosas en el México contemporáneo. El tercero aspecto, y el más importante aquí, está destinado a dar cuenta de cómo se genera el proceso de adhesión de un individuo al cuerpo institucional del franciscanismo; qué mecanismos son utilizados y a qué nivel de la configuración personal trabajan. Para esta tercera parte he priorizado una escritura de corte narrativo, pues considero, junto con Fassin (2016), que los relatos etnográficos tienen la posibilidad de reconstruir las relaciones vívidas de grandes capacidades heurísticas para hacer inteligibles aspectos teóricos importantes.

\section{HACIA UNA SOCIOANTROPOLOGÍA DE LA VIDA CONSAGRADA CATÓLICA}

Las órdenes religiosas son un agregado sui generis dentro de la organización jerárquica de la Iglesia Católica. Sin embargo, únicamente los religiosos varones son quienes administran los templos y, en algunos casos, pueden llegar a ocupar cargos de gobierno en las diócesis locales. Pero la relación entre los religiosos y las posturas políticas y pastorales de los demás miembros institucionales de la Iglesia (como el clero secular u obispos) no siempre ha estado en sintonía de intereses. En este sentido, el catolicismo representa unidad doctrinal y, al mismo tiempo, diversidad de interpretaciones y proyectos socio-eclesiales (Blancarte, 2014). De la Torre (2006) documentó este hecho en la distinción entre jerarquía y laicos para el caso de la región occidente de México. La autora concibió a la Iglesia católica como una institución transversalizada: "que contemplara la horizontalidad de relaciones informales, pero que al mismo tiempo no desdibujara o relativizara las relaciones objetivas del poder jerárquico (De la Torre, 2006, p. 131). 
Sin embargo, y a pesar del valioso aporte para problematizar al catolicismo tomando el punto de vista de los diversos agentes que integran la institución, las condiciones metodológicas de la investigación realizada por la autora (centrarse en los laicos), dejaron a la jerarquía como un cuerpo que sólo llega a la reflexión por los movimientos ocurridos fuera de éste. El registro de la jerarquía que hace De la Torre se reduce a las reacciones de aceptación o rechazo que suscitan las presiones de los laicos y sus formas de organización. En términos generales, este modo de representar a la jerarquía católica no se desmarca del tratamiento común de las ciencias sociales mexicanas: tomar exclusivamente el punto de vista de los más altos cargos y, en gran medida, considerar al clero como un grupo coherentemente homogéneo, sin divisiones al interior, y preocupado por defender el status y el dogma (Padilla, 2015). Este modo de pensar sobre los consagrados católicos no tiene sensibilidad de la diferencia al interior del aparato burocrático eclesial debido a que se concentran en el aspecto sociológico y funcionalista de su pertenencia institucional, obviando un abordaje cultural de la religiosidad, lo simbólico y la experiencia (Mella, 2008).

En el esfuerzo de construir un lugar de observación teórica-metodológica sobre este sector eclesial desde otra perspectiva que la dominante en las investigaciones en México, es necesario ofrecer un acercamiento cultural sobre el catolicismo en general y la vida consagrada en particular. La particularidad de la vida religiosa dentro del catolicismo reside en dos aspectos principales: a) su ambivalencia institucional; y b) su potencial cultural de construcción de significados. Si bien los religiosos son reconocidos como parte de los representantes de culto, sólo entran al círculo rector de las diócesis particulares y de la curia vaticana de manera discontinua; es decir, son agregados que se desarrollan paralelamente al cuerpo de cargos instituidos en la organización eclesial y sólo en algunas ocasiones hacen parte de ésta. Habrá que recordar para comprender esto, que la vida religiosa nació como un movimiento no sacerdotal en el que diversos creyentes se congregaban o retiraban en soledad para exigirse una vivencia más radical del ser cristiano. Esta condición les permite un movimiento pendular hacia 
dentro y hacia fuera de la institución eclesial, y de aquí la "libertad" que históricamente han presentado para entrar y salir de los cánones católicos. El espacio que se genera por las interacciones entre las congregaciones religiosas y el resto de la institución católica puede ser concebido como una "arena" político-religiosa del catolicismo institucional, en la que no sólo importa caracterizar el lugar que ocupa cada uno de los actores en el conjunto de normas, puestos o cargos oficiales; sino también demostrar la transformación de los paradigmas espirituales en símbolos y metáforas que movilizan a los individuos. Los aportes de Turner (1974) hacia la noción de arena en el campo de la antropología política, permiten elaborar y señalar este marco de relaciones que se da dentro de la jerarquía y que ha sido poco visibilizada en las investigaciones sobre el catolicismo en México.

Por otro lado, en la larga y compleja historia de la Iglesia católica, ha sido de la vida religiosa de donde han surgido buena parte de los movimientos de renovación espiritual y cultural más importantes que han dado forma no sólo a la institución religiosa, sino también al conjunto social y cultural externo a ella. No son pocos quienes señalan que la sociedad medieval, con sus luces y sombras en cuanto a religiosidad y cultura se refieren, no puede comprenderse sin el papel jugado por los monasterios benedictinos y la labor bibliotecaria que cargaron a sus espaldas por varios siglos. En otro aspecto, el cúmulo de significados del catolicismo ha sido gestado en gran medida por la experiencia de los religiosos y religiosas consagrados. Las ideas cristianas de "mística", "renovación", "conversión", "disciplina", "meditación", "comunión" o "salvación", por mencionar algunas, fueron cargadas de sentido a partir de la espiritualidad dentro del claustro y en gran medida representan el centro del "sistema de significaciones" (Geertz, 2003, p. 117) de la vida religiosa consagrada. Estas concreciones ideológicas, en muchos casos produjeron rechazo y persecución por parte de la alta jerarquía católica; demostrando, aun en el plano simbólico, la peculiar distancia o ambivalencia de la vida religiosa frente al resto de la jerarquía institucional.

Con todo, los significados construidos en la vida religiosa católica no son petrificaciones ahistóricas de algún sistema clasificatorio del mundo; sino 
que están en permanente reconstrucción por medio de la práctica religiosa de los consagrados. En el mundo conventual, tan minuciosamente organizado para la autoobservación, el lugar metodológico para registrar la puesta en práctica de los referentes simbólicos es la vida ritual cotidiana y sus vínculos con la corporalidad. Como ha mostrado Csordas (1990, 1994, 2011), la experiencia corporizada posibilita más que comprobar el accionar cultural de un cuerpo representado de antemano; analizar la cualidad somática de ser-en-el mundo. Por ejemplo, las recientes investigaciones en monasterios femeninos (Lester, 2003; Jonveaux, 2011, 2012; Khonineva, 2019) señalan cómo existen reinterpretaciones sobre el celibato y la ascesis corporal gracias a la inclusión de nociones seculares sobre el género y la libertad individual. Las monjas de claustro reelaboran la tradición contemplativa del "control" corporal en primacía del espíritu, y construyen concepciones alternativas en donde el cuerpo, las sensaciones, el intelecto y el bienestar forman aspectos claves de la meditación y oraciones monásticas. Así, el análisis del ámbito simbólico de la vida consagrada no nos conduce a desempolvar significados anclados en los contextos donde surgieron, ni se reducen a la búsqueda de un sistema cerrado de representaciones; sino que requiere vincular los “esquemas semióticos” con el momento y el lugar de su puesta en práctica por sujetos consagrados específicos.

Por lo tanto, es necesario atender tres dimensiones de las órdenes religiosas que se encuentran articuladas de manera compleja: a) su inevitable realidad institucional, organizacional y jerarquizada con respecto al resto de la burocracia católica; b) su componente cultural y simbólico para construir referentes de sentido; y c) su actualización, reinterpretación y reinvención de los dos aspectos anteriores a partir de prácticas religiosas concretas en la vida ritual, eclesial, política y social cotidiana. Por lo tanto, y tomando en cuenta las anteriores reflexiones, la Orden de Frailes Menores es concebida aquí como un cuerpo de profesionales o especialistas del catolicismo con relaciones ambiguas para con el resto del aparato burocrático clerical, que elabora y resignifica tanto dentro como al margen de la pirámide eclesial, formas de organización y pertenencia institucionales propias, además de 
configurar un cúmulo de significados de orientación de sentido mediante símbolos y prácticas propias de la religiosidad de la vida consagrada. De este modo, el micro cosmos del convento franciscano de Chiapas, en tanto punto de observación etnográfica, necesita ser puesto en el contexto social e institución más general, y así articular los diversos niveles de análisis propuestos arriba. Para nuestro caso, esto significa reconstruir el proceso de fundación de la provincia franciscana del sureste mexicano, pues el nacimiento de esta entidad administrativa expresa puntualmente este vaivén entre la institución y la religiosidad, entre los elementos comunes del franciscanismo asentado en el sur de México y las experiencias subjetivas y corporizadas de cada uno de los frailes. ${ }^{7}$

\section{LA FORMACIÓN HISTÓRICA DE LA PROVINCIA FRANCISCANA SAN FELIPE DE JESÚS}

La presencia franciscana en la frontera sur de la Nueva España se organizó bajo la provincia San José de Yucatán (fundada en 1559); sin embargo, ésta quedó disuelta con la exclaustración de todos los religiosos que dictaron tanto la ley de expulsión de españoles de 1827 como las leyes de Reforma de 1860 (Chauvet, 1989). Con todo, y justamente porque una congregación religiosa necesita pensarse mas allá de una simple corporación, la venida a menos de los frailes menores responde no sólo a los embates jurídicos del naciente Estado mexicano, sino también al agotamiento del carisma misionero franciscano, a la crisis de identidad religiosa, y a la falta de proyectos congregacionales en el contexto del cambio del régimen político (Morales,

7 Un símil inspirador de este ir y venir de un saber hacer práctico, corporal y rutinariamente aprendido en un ámbito micro, hacia patrones económicos y sociales más amplios es el trabajo etnográfico en un salón de boxeo de Wacquant (2006). En este magistral estudio, el autor no duda en vincular el ring, el sparring y sus largas horas de aprendizaje corporizado con la calle, el barrio y las condiciones de marginación que les eran comunes a quienes se formaban como pugilistas.

Debates do NER, Porto Alegre, ANo 20, N. 37, P. I69-200, JAn./JUl. 2020 
1993); por ejemplo, habrá que recordar que el último esfuerzo por justificar la presencia de los frailes en la política religiosa de la Nueva España, fue la fundación, hacia finales del siglo XVII y durante todo el XVIII, de los Colegios de Propaganda Fide (a pesar de que éstos estuvieran directamente bajo dirección vaticana, más que de las provincias franciscanas novohispanas), justo cuando se daba la secularización de las doctrinas y sólo quedaban las misiones del árido norte o de la impenetrable selva del sur (Rubial, 2013).

El inicio del siglo XX fue el momento más crítico de los franciscanos en México. En 1908 la curia general de la orden suprimió todos los Colegios de Propaganda Fide y para organizar a los frailes que quedaban activos, redujo las seis provincias que todavía existían, a tres comisarías (es decir, una figura administrativa menor, por el reducido número de personal). ${ }^{8}$ No obstante, en el marco político del modus vivendi (pacto firmando en 1929 entre el Estado y la Iglesia para poner fin a la guerra cristera) que representó el contexto propicio para que la jerarquía católica experimentara un incremento generalizado en el número de diócesis y sacerdotes (Meyer, 2005), los franciscanos también comenzaron a reestablecer su presencia en México. Tal fue el aumento de frailes y la estabilidad institucional vocacional que, para 1950, la comisaría del Santo Evangelio retomó el status de provincia y regresaron a territorio mexicano un grupo numeroso de frailes que se habían retirado a las misiones de Estados Unidos. Justamente de esta entidad franciscana (Santo Evangelio) comenzó el retorno de los frailes al sureste de México (Yucatán, Quintana Roo, Campeche, Chiapas y Tabasco).

En 1948, el entonces obispo de Yucatán, Fernando Solórzano, pidió al gobierno del Santo Evangelio le enviaran franciscanos para atender el

8 Durante la Colonia, las seis provincias franciscanas fueron las del Santo Evangelio (centro de México); San José de los Naturales (Yucatán); San Pedro y San Pablo (Michoacán); San Francisco (Zacatecas); Santiago (Jalisco); y Dulce Nombre de Jesús (Chiapas y Guatemala). No obstante, y después de suprimir estas provincias para establecer las comisarías de Jalisco, Michoacán y México (respetando el nombre de cada una de ellas); según las estadísticas oficiales de la orden, en 1885 sólo había 25 frailes en la primera, 85 en la segunda y 44 la tercera, respectivamente (Chauvet, 1989).

Debates do NER, Porto Alegre, ano 20, N. 37, P. I69-200, JAN./Jul. 2020 
convento de Izamal, Yucatán. Después de esta incursión, durante las décadas de 1950 y 1960 le siguieron varias oleadas de frailes que poblaron el resto de los estados del sureste. La política religiosa de la orden franciscana tomó esta etapa de su quehacer como parte de un nuevo proyecto de "misión". En los documentos oficiales de esa época, la orden habla de retomar el trabajo de conversión y evangelización de una buena parte del territorio mexicano que históricamente se ha mostrado reticente para asumir la observancia católica (Viqueira, 1997). Para el caso de las montañas del norte de Chiapas (lugar en el que se encuentra el noviciado aquí estudiado), Lisbona (2004) registró los recuerdos que sobreviven en la población local acerca de los enfrentamientos ocurridos por estos ańos entre los frailes misioneros y los sistemas de cargos indígenas, por hacerse del control de templos e imágenes. De acuerdo a lo apuntado teóricamente, no es casual que precisamente fueran franciscanos lo requeridos para volver a evangelizar estos territorios, ni que los mismos frailes estuvieran animando su "retorno" al sureste mexicano, echando mano del referente institucional como misioneros, pues la "misión" ha sido el bastión ideológico para legitimar las incursiones franciscanas. Ser religiosos misioneros ha sido parte de la especificidad carismática del franciscanismo, y se ha construido en un largo proceso de varios siglos que recogen diversas experiencias en el mundo, desde la diáspora hacia Oriente Medio cercana a los tiempos de la fundación de la orden (García, 2009), hasta la llegada a tierras mesoamericanas (Rubial, 1996). 
Sin embargo; debido a la celebración del Concilio Vaticano II, ${ }^{9}$ los frailes de las "misiones del sureste" ${ }^{10}$ comenzaron a cuestionar su pastoral e iniciaron una abierta confrontación con las autoridades de la provincia del Santo Evangelio, asentada en el centro de México. Por más de veinte ańos se anclaron en disputas, denuncias y descalificaciones que tachaban de burgueses a unos y comunistas a otros. El resultado de este conflicto fue la fundación en 1995 de la provincia San Felipe de Jesús, con sede en el convento de Izamal, Yucatán. Con esta nueva entidad franciscana, los frailes buscaban un verdadero diálogo entre el carisma franciscano y las formas religiosas locales. $\mathrm{Si}$ bien en este acontecimiento se puede observar la búsqueda de un modo de ser franciscano sensible a la realidad sociopolítica del sureste, no deja de asomarse una utilización del marco discursivo generado por la Teología de la Liberación, y así acomodarse a las nuevas condiciones de la vocación religiosa en México. El perfil de los candidatos en la orden franciscana, al menos en lo que respecta a la provincia del Santo Evangelio y justo en las décadas previas a la aparición de la entidad del sureste, estaba marcado por una tendencia importante hacia sujetos venidos de ámbitos rurales y con baja escolaridad. Antes de este momento, las órdenes religiosas no tenían

9 Este Concilio se celebró de 1962 a 1965 y su impacto para el catolicismo latinoamericano en general y para las órdenes religiosas asentadas en Latinoamérica en particular, ha sido documentado profusamente, especialmente en sus derivaciones teológicas liberacionistas (cfr. Löwy, 1999). En términos generales, puede decirse que este concilio generó un momento de profunda revisión teológica y pastoral al interior de las órdenes religiosas y los institutos de vida consagrada. De este movimiento se ha puesto más atención en las proyecciones políticas llevadas a cabo por los religiosos, pero las ciencias sociales se han preocupado menos por los procesos que dieron tales resultados. En este punto, resaltaría no sólo las modificaciones institucionales que se fueron impulsando, como el abandono de grandes casas de formación para rearticular su forma de vida en pequeñas comunidades asentadas en periferias urbanas y rurales (Falcó Pliego, 2004); sino también en la reinterpretación del sentido de mucho de los signos y fundamentos de la vida religiosa (Richi, 2018).

${ }^{10}$ Así llamaron los superiores provinciales del Santo Evangelio a las comunidades de franciscanos fundadas en los estados del sur de México. 
como problema institucional el origen socioeconómico de sus candidatos. El ambiente urbano y de clase media todavía generaba gran parte del grueso de vocaciones; sin embargo; durante la segunda mitad del siglo pasado, las convulsiones culturales desataron al interior de la Iglesia una crisis vocacional de la cual todavía no sale, y ocasionaron el poco atractivo de la consagración religiosa para los sectores medios y alfabetizados.

A la par de las pretensiones liberacioncitas, los franciscanos de la nueva entidad en el sureste de México, vieron la opción preferencial por los pobres y la inculturación del evangelio promovido por las Conferencias de Medellín y Puebla como la oportunidad para justificar la incorporación de población rural e indígena al séquito de religiosos. Los documentos de fundación de la provincia del San Felipe de Jesús expresan claramente este hecho: la estructura de la formación para nuevos frailes está fundamentada en la inclusión de individuos étnicamente diversos y bajo criterios de inclusión y respeto. Este es el contexto institucional en el que hay que situar la "necesidad" de los franciscanos por fundar una provincia en el sureste de México y de construir un noviciado en la zona norte de Chiapas. Así, de la grave crisis de inicios del siglo XX, los frailes menores pasaron a reacomodarse en las nuevas condiciones socioculturales de la religión en México y construyeron el trabajo misionero inculturado como el discurso que sirve para asentar su presencia en el sureste mexicano y asegurarse el ingreso de vocaciones de sectores que antes no sobresalían entre las filas de los frailes.

\section{EL NOVICIADO FRANCISCANO Y LA TRANSFORMACIÓN CONVENTUAL DEL YO}

El noviciado es la etapa más importante en la formación de la vida consagrada (Lavrin, 2015). Es un momento de prueba, de autoobservación y de separación física y simbólica que busca discernir la idoneidad del sujeto para la vocación, franciscana en este caso. La organización del tiempo y del espacio dentro del convento-noviciado pueden ser considerados a partir 
de las nociones sociológicas de las instituciones totales y la microfísica del poder (Goffman, 1972; Foucault, 2010): tanto la regularización absorbente de la vida cotidiana como el encauzamiento del sujeto por medio de múltiples técnicas disciplinarias dejan poco espacio para la espontaneidad. Sin embargo, contrario a los nosocomios mentales y las prisiones analizados por Goffman y Foucault, un noviciado está habitado por sujetos que, en principio, han entrado conscientemente y de manera voluntaria. Por lo tanto, es necesario esforzarse por comprender la "racionalidad nativa" conventual (Ludueña, 2003, 2008), relacionando el sistema de símbolos (en constante recomposición histórica) que le dan coherencia y razón de ser, con la observación de prácticas espirituales cotidianas. ${ }^{11}$ De no tomar en cuenta este aspecto, la experiencia de quienes ingresan a este tipo de regímenes religiosos y los elementos que lo componen, estaría reducida al sinsentido y a la más sombría ininteligibilidad. Así, el encierro, la separación física y el silencio, por mencionar tres aspectos centrales en la estructura conventual, simplemente se reducirían a suerte de tormento incomprensible y soledad masoquista. Aunado a esto y desde una mirada antropológica (Turner, 1988; Van Gennep, 2008; Eliade, 2008), el noviciado consiste en una ceremonia de iniciación que expresa un tránsito ritual de un estado religioso (laico) a otro (religioso franciscano). Es decir, marca la adhesión a un sistema de creencias y a una comunidad eclesial, y dota a los sujetos un yo confesional que modifica aspectos sustanciales de la subjetividad (Masferrer, 2013; Falcó Pliego, 2004).

${ }^{11}$ Csordas (2011, p. 97) ha mostrado para el caso de los rituales de sanación tanto del movimiento carismático católico como del espiritismo, las virtudes explicativas de abstenerse "de invocar cualquier categoría que no sea la de la 'experiencia' [corporizada de los sujetos]". Para este autor, partir de esta suerte de corporización del ser-en-el mundo (Csordas, 1990, 1994), obliga a rechazar la dualidad semiótica-fenomenología (objeto-sujeto) de la epistemología de las ciencias sociales e impulsa a buscar trascender las categorías antropológicas comúnmente utilizadas para estudiar las "posesiones", los "estados alterados", o el "trance". Justamente esta invitación es lo que anima la reconstrucción etnográfica de la "experiencia corporizada de ser-en-el convento" del siguiente apartado.

Debates do NER, Porto Alegre, ano 20, N. 37, P. I69-200, JAN./Jul. 2020 
Hacer etnografía de la vida consagrada católica exige, entonces, tomar en consideración el sentir de los sujetos a partir de su transitar por medio de silencios, movimientos corporales, plegarias y referentes simbólicos de significados. Este imperativo metodológico en el diseño etnográfico resulta de gran consideración en un momento histórico en que la vida religiosa ha perdido legitimidad en las sociedades occidentales, y es considerada o un lastre del pasado destinada a desparecer o bien un conjunto de prácticas extrańas de gente que envuelve "reales motivaciones psicológicas o económicas" en un manto religioso. Estos aspectos me permitieron apuntar la importancia de observar los dispositivos conventuales en tanto "modos somáticos que se cultivan conscientemente" (Csordas, 2011, p. 88), y así explicar la resocialización que tiene lugar en esta etapa formativa. De este modo, la intención es basar el análisis del ser religioso no sólo en aspectos sociológicos de la organización jerárquica institucional, sino también en la religiosidad corporizada que permite la reinterpretación de lo individual. Por lo tanto, es necesario hacer énfasis en uno de los mecanismos centrales en este proceso: el entramado disciplinario para la observancia de sí; es decir, la articulación de una serie de tecnologías del yo en el funcionamiento cotidiano. Finalmente, y aunado a la consideración sobre el relato antropológico apuntada en la introducción; para la siguiente reconstrucción etnográfica utilicé como recurso narrativo, la distinción típica de las horas 
canónicas (Liturgia de las Horas) que estructuran la liturgia conventual, ${ }^{12}$ esa misma que sirvió a Eco (1999) para atrapar al lector en los enredos del joven novicio Adso de Melk.

\section{UNA JORNADA EN LA INICIACIÓN FRANCISCANA}

\section{LAUDES}

Tocan a la puerta de la habitación y se escucha: "Ave María purísima". Son las 5:30 a.m. Ha comenzado el día en el noviciado franciscano. Al no obtener respuesta, la voz que está detrás llama de nuevo alargando la última vocal: "Ave María purísima”. Contesto mientras lucho por mantenerme despierto: "Sin pecado concebida". Se repite el pequeño responso mariano en cada puerta y con esto se consigue despertar a todos los novicios. Mientras me preparo para salir, se oye a Alan, novicio que funge de sacristán de la comunidad, decir en voz melodiosa de plegaria: "Bendito y alabado sea el santísimo sacramento del altar, los dolores de su purísima madre María santísima, nuestro padre san Francisco. A laudes hermanos, es hora de alabar a Dios y a su santísima madre”.

${ }^{12}$ La Liturgia de las horas, antiguamente llamada Oficio divino, es la organización de algunos pasajes bíblicos y de los 150 salmos en siete rezos diarios: Vigilias, Laudes, Tercia, Sexta, Nona, Vísperas y Completas. Esta ordenación está pensada de tal manera que se puedan leer todos los salmos a lo largo del ciclo anual litúrgico. El horario del noviciado franciscano no contempla las Vigilias, que tendrían que hacerse cerca de las 4:30 a.m. o 5:00 a.m. Tampoco se hacen Tercia (9:00 a.m.) y Nona (3:00 p.m.). Éstas últimas, junto con Sexta (entre 12:00 a.m. y 1:00 p.m.) toman su nombre a partir del recuento de las horas de sol: Tercia refiere a la tercera hora después de la salida del sol, Sexta y Nona a la sexta y novena hora respectivamente (Longeat, 2008). Actualmente, es común que sólo los monasterios de órdenes de vida contemplativa realicen todas las horas establecidas. 
En seguida, se advierten tres toques de campana. Las puertas de las habitaciones se abren y cierran aquí y allá, unas después de otras. El pasillo tenuemente iluminado del claustro es invadido por cuatro sayales franciscanos que avanzan hacia la capilla conventual. Para llegar a ella hay que salir de los pasillos techados y caminar por un empedrado que va hacia los jardines. La arquitectura fue diseñada para reproducir el modelo de San Damián, aquella iglesia en Asís en la que según la tradición franciscana se dio el llamado de Francisco para iniciar su movimiento mendicante. Está adornada en el dintel con las dalmáticas, uno de los escudos más conocidos de los franciscanos: dos brazos cruzados con las manos estigmatizadas que representan a Francisco y a Jesucristo, por encima de éstos una cruz, y, por debajo, un mundo; todo esto dentro de un círculo hecho por el cordón de tres nudos del hábito franciscano.

No es una procesión, simplemente acudimos al primer rezo del oficio litúrgico. Al llegar, los otros cuatro novicios y los dos formadores ya están en sus asientos. Nadie saluda, entramos haciendo una reverencia y buscamos el lugar que nos corresponde en las dos filas de sillas metálicas colocadas en las paredes laterales de la capilla. Alan frente al teclado; es el único que sabe armonizar los salmos. A la cabeza de ambas filas, en los puestos más cercanos al altar, se colocan César y Federico, quienes iniciaran con la primera estrofa en cada salmo. Los demás nos acomodamos detrás de ellos. Los dos formadores al final, uno en cada lado. Rodrigo abre la Liturgia de las horas y pregunta discretamente a Marcelo: “ ¿Hoy tocan estos salmos?” Éste, asiente con la cabeza. Todos alistamos los libros. Fabián tose. El sueño todavía pesa en los ojos e Ismael bosteza disimuladamente. Se evitan movimientos rápidos que puedan llamar la atención. Nadie se ve a los ojos, todos miramos fijamente hacia algún punto. Hacerse fraile requiere la incorporación paulatina de dispositivos corporales y mentales. Así lo deja ver Marcelo cando comenta que la "vida [en el noviciado] es demasiado dura porque no es hacer lo que tú quieras, sino es empezar a formarte los ideales de la orden, de empezar a comulgar con ciertas ideas que al principio se te hacían muy extrańas”. 
La apropiación de la práctica ritual de esta tradición litúrgica es uno de ellos. Introduce a los iniciados en un tiempo ritual que procura el cuidado de sí (Lester, 2003). En el noviciado franciscano, la experiencia de iniciación transcurre en el marco temporal de la ritualización de la vida cotidiana que se genera a partir del rezo de la Liturgia de las horas. Liturgia y biografía se relacionan de tal manera que la segunda es revisada constantemente al paso de los rezos: "el ritual sirve para expresar el estatus del individuo en el sistema estructural en el cual se encuentra en la actualidad" (Leach, 1954, p. 11). El ritual litúrgico conventual es autorreferencial (Rappaport, 2001): contiene información que los iniciados se dicen a sí mismos. Es el marco retórico e interpretativo de la iniciación ritual y no se reduce únicamente a un conjunto de textos, plegarias o técnicas de meditación; son enunciados que los novicios tienen a la mano para pensar sobre sí y construir su iniciación.

"Del sermón de la resurrección de Cristo por san Gregorio de Nisa" dice Tito después de ponerse de pie, en un momento de silencio al terminar de cantar los salmos. Continua:

Ha comenzado el reino de la vida y se ha disuelto el imperio de la muerte. Han aparecido otro nacimiento, otra vida, otro modo de vivir, la transformación de nuestra misma naturaleza. ¿De qué nacimiento se habla? Del de aquellos que no han nacido de sangre, ni de amor carnal, ni de amor humano, sino de Dios (Oficio de lectura del lunes V del Tiempo Pascual, Liturgia de las Horas, 2014, p. 829, subrayado mío).

El ingreso a la vida religiosa puede tomarse como un momento que replantea la vida toda del sujeto. Así lo percibe César, para quien el inicio del noviciado significó "poner pausa en mi vida [...] un paréntesis para las experiencias nuevas [...] para encontrarme conmigo mismo". Esto supone intensificar la vivencia religiosa personal; por ejemplo, Alan señala que el comienzo del noviciado supuso "sentir más fuerte el compromiso". 
8:00 a.m. La campana suena nuevamente tres veces. Los novicios van saliendo de las habitaciones con sus hábitos recién puestos después de habérselo quitado para realizar los aseos del convento. Se dirigen al comedor. Antes de tomar asiento, alguno de los formadores realiza la bendición de los alimentos. La dimensión corporal aparece aquí de manera más expresa. La iniciación conventual supone una transmisión de técnicas que modelan el cuerpo. Salvador, de más de 70 años y fraile que funge como segundo al mando dentro del noviciado, presenta el somatotipo que se espera tradicionalmente como resultado de la ascesis cristiana: cuerpo lineal con pocas cantidades de grasa cutánea y desgastado por el trabajo manual de tareas campesinas o artesanales. Siempre es el último en servirse los alimentos e intencionadamente toma poca cantidad. Come despacio y no consume carnes rojas. La práctica regulada que tiene de su cuerpo es una enseñanza a tomar en consideración siempre que te topas con él. La vida religiosa es un fenómeno bio-antropológico. Todo el sujeto está implicado en la iniciación ritual: el cuerpo y la mente son modelados según comportamientos estandarizados, hábitos alimenticios y actividades físicas.

Mientras se comienza con el desayuno, Rodrigo ha tomado un libro de la estantería del comedor. El silencio sólo se interrumpe tenuemente por el chillar de cubiertos y platos, y algunos comentarios en voz baja. "Santos franciscanos para cada dia-comienza diciendo Rodrigo-. Viernes 15 de julio. San Buenaventura de Bagnoregio, fraile, obispo cardenal y doctor seráfico”. A la par del consumo de los alimentos, todas las mañanas los novicios escuchan narraciones hagiográficas que exaltan la vida y vocación franciscanas. La similitud entre estas narraciones y las construidas por los novicios para justificar su ingreso a la orden franciscana es digna de mencionarse. En ellas hay un proceso de reacomodo del yo a partir de una hermenéutica hagiográfica religiosa. La estructura de las narraciones que diariamente escuchan los novicios contiene tres elementos básicos: a) el llamado a la vida franciscana; b) las indecisiones o dificultades para responder; y c) la respuesta favorable que acomoda y reinterpreta las vivencias anteriores a su conversión y entrada. Por estos aspectos, la toma de alimentos es un 
ejercicio de escrutinio del yo. La pedagogía conventual y el trabajo de la iniciación no descansan.

SEXTA

Hace media hora que ha terminado la clase sobre historia franciscana. Fabián y César aprovechan el tiempo que tienen antes de la siguiente actividad para lavar algo de su ropa personal. Se dirigen a los lavaderos comunes que se encuentran a un costado de la hospedería. Al cabo de un tiempo, Alan se dirige al centro del claustro y hace sonar la campana llamando a Sexta (01:00 p.m.). Los novicios se reúnen en el jardín interior del claustro. En lugar de cantar salmos y leer fragmentos de libros bíblicos, rezan siete padrenuestros. La siguiente actividad es la comida; este es un momento de distensión dentro de la jornada. No hay lectura en el comedor como en el desayuno y la sobremesa puede extenderse hasta casi las 3:00 p.m. De manera regular, los novicios recuerdan anécdotas vividas en las etapas de formación anteriores al noviciado (principalmente del postulantado en Yucatán). Hablan de personas por todos conocidos con las que entablaron amistad. Una y otra vez repasan particularidades de color y forma de hábitos religiosos que vieron en religiosas y religiosos de Yucatán. Se desarrollan debates acerca de cada congregación y de su eficacia en el quehacer de la Iglesia. Es un esfuerzo por dotar de identidad y sentido a su propia opción personal de ingresar con los franciscanos. Los puntos centrales de la minuciosa comparación entre hábitos religiosos expresan la certeza que brinda a los novicios portar un hábito que los distingue de los demás religiosos, reconocer el lugar que tienen en la institución y diferenciarse de las otras congregaciones religiosas. Cerca de las 3:30 p.m., los iniciados practican algún deporte. Este momento no puede comprenderse sólo como esparcimiento y ocio. Dentro del tratamiento corporal de la iniciación conventual adquiere otra significación.

Me gusta el momento de deporte -dice Alan-, ayuda a gastar energías. Es necesario estar en actividad constante para evitar pensamientos lujuriosos y

Debates do NER, Porto Alegre, ano 20, N. 37, P. I69-200, JAN./Jul. 2020 
la masturbación. A medio día no te vayas a acostar o a descansar una hora porque de ahí vienen los pensamientos esos [...] por eso nos proponen comer menos de lo que acostumbrábamos, o sea, comer lo suficiente para mantenernos activos, tampoco te vayas a enfermar, pero no caer en la gula porque cuando tu cuerpo tiene demasiadas energías y ya no sabes dónde gastarlas, a lo último que recurres es a la masturbación. Por eso no duermo de día, por lo mismo, prefiero mantenerme ocupado en otras cosas.

La disciplina de la iniciación conventual mantiene tensión constante sobre el cuerpo: el escrutinio de sí también es escrutinio del cuerpo.

\section{VÍSPERAS}

Suena nuevamente tres veces la campana del claustro. El reloj marca las 7:00 p.m. Los novicios se reúnen en la capilla para la celebración de la Eucaristía. Es uno de los momentos clave dentro de la jornada conventual, no sólo por la importancia que le adjudica la doctrina y práctica católica, sino porque se convierte en una situación puntual en la que los novicios se ven nuevamente confrontados por la lógica de la iniciación: examinar su biografía en busca de la confirmación de la vocación. Los extractos bíblicos que se leen durante el ritual de la misa son interpretados desde el contexto de la transformación iniciática. La retórica del ritual nuevamente aparece para ser usada por los novicios en la justificación de su entrada al noviciado y su permanencia en la orden franciscana. Después del contenido de los salmos de la Liturgia de las horas, las lecturas bíblicas de la misa son los elementos que generan procesos de subjetivación iniciáticos; es decir, de emergencia del sujeto consagrado:

Son ustedes mis amigos si cumplen lo que les mando. Ya no les llamo servidores, porque un servidor no sabe lo que hace su patrón. Los llamo amigos, porque les he dado a conocer todo lo que aprendí de mi Padre. Ustedes no me eligieron a mí, he sido yo quien los eligió a ustedes y los preparé para que vayan y den fruto, y ese fruto permanezca. Así es como el Padre les concederá todo 
lo que pidan en mi Nombre (Juan 15: 14-16, versión latinoamericana 1972, subrayado mío).

Durante la misa se rezan las Vísperas, la penúltima hora canónica de la oración de los religiosos. Nuevamente aquí, los esquemas de subjetivación se hacen presentes. La lectura bíblica va disponiendo al novicio para el continuo escrutinio de sí, como comenta Tito:

En la noche siempre avanzo en la lectura [bíblica] para el día siguiente, veo a veces tan extensa la lectura, este, me topo con, no sé, un verso tan pequeño que me ayuda a crecer o que choca en mi persona, toy haciendo esto, toy haciendo esto, y a veces no las cumplo, ¿no?

Terminada esta celebración religiosa la comunidad se dirige al comedor en donde ya están listos los alimentos para la cena.

\section{Completas}

10:00 p.m. Suena por penúltima vez la campana del claustro. La capilla del noviciado espera la llegada de los novicios para el rezo de Completas. Casi al terminar el oficio litúrgico uno de los novicios lee un fragmento de los cuatro evangelios que corresponde al siguiente día, y así todos puedan comenzar a analizarlo. "Cuando estaba afuera no tenía conciencia de cómo pasaban los días, no me detenía tanto en pesar las cosas que se pueden hacer... Ahora creo que cada momento del día tiene su importancia”. Así resume Tito la significación ritual del paso de las horas. El entramado disciplinario configura la disposición del novicio para el paso del día. En el convento se levantan con la invitación para orar y a lo largo de las horas el mismo ritmo ritual genera subjetivaciones específicas. Cuando esto ha finalizado, abandonan la capilla en fila para recibir agua bendita. A las 10:45 p.m. Alan pasa rociando agua bendita sobre las puertas de cada dormitorio habitado. Se escucha por última vez la campana. Tres toques de ésta señalan el inicio del tiempo de silencio y descanso hasta la actividad del siguiente día. 


\section{EL MUNDO EN EL CONVENTO:}

\section{LA RELACIÓN ENTRE VOCACIÓN Y SOCIEDAD}

Los dispositivos conventuales expuestos arriba tienen detrás las características típicas de las pruebas iniciáticas: prohibiciones y reglamentaciones que buscan examinar la voluntad. La repetición de estas prácticas implica una compleja organización religiosa de elementos simbólicos y materiales. El silencio durante las lecturas en el comedor, la disposición corporal en los ritos, el deporte, la salmodia en comunidad y el escrutinio interior a lo largo de la jornada, representan la constitución del sujeto dentro del tejido cultural de la orden franciscana. Estos elementos toman significado a partir del objetivo principal del noviciado: la adecuación del sujeto a las formas religiosas de la orden. En el trasfondo de estas tecnologías se está generando la transformación del yo que busca asegurar la adhesión institucional. La fuerza de la experiencia de la iniciación se fundamenta en esta suerte de hierofanía del sí mismo, es decir, una revelación del sentido de la existencia del sujeto. Por tal motivo, la historia personal es releída desde este proceso y se busca dar sentido a depresiones pasadas, separación de los padres, migración familiar o desengaños amorosos. El caso más sugerente de este proceso, en el que la biografía es puesta en trabajo durante la jornada conventual y resulta en una nueva comprensión del pasado, es el de Tito, pues lo llevó a dar significado a un evento trágico que consternó a toda su familia: el asesinato de su hermana a las afueras del Hospital " 5 de Mayo" de Tuxtla Gutiérrez, Chiapas. Para los padres de Tito, esta penosa e inesperada pérdida hace que perciban su entrada con los franciscanos como otra ocasión para vivir la separación y la falta de un hijo. La cercanía de ambos acontecimientos apremiaba tal postura, en abril de 2015 asesinaron a la hermana de Tito, y en julio de ese mismo año ya había ingresado al postulantado de los franciscanos. Sin embargo, la experiencia conventual y el trabajo subjetivo de su historia personal, posibilitan a Tito resignificar la tragedia. En medio del desgarre familiar que supuso esta muerte, él confirma su vocación religiosa a partir de un acontecimiento sucedido el 10 de mayo de ese mismo 2015: 
Mi hermana y mi madre eran muy unidas, y el día de las madres tenemos la costumbre de juntarnos todos, y como a eso de las ocho o nueve se sintió un aroma a rosa, muy fresca, muy rico, ahí en el pasillo, en el pasillo en donde estábamos. Duró hasta las seis de la tarde y las personas que llegaban a visitar, pues, sentían ese olor y ya pasando las seis de la tarde como que se desvaneció [...] Desde mi fe pienso que fue un regalo de despedida [de mi hermana para mi madre] porque solamente fue ese día especial. Siempre le llevaba algo, salían a pasear o a comer [...] Creo que ingrese aquí para ayudar a otras personas que sufren esto, como que estar ahí con ellos cuando pasen ese momento, creo que es lo único que puedo hacer, y ¿por qué? Porque mi hermana también me apoyó bastante, le platiqué de mi inquietud y me dijo: yo no me meto, pero es tu decisión, si tú te gusta, pues, adelante, yo te apoyo, puedes dejar este trabajo.

Gracias a la relación laboral de su hermana con el Hospital "5 de Mayo", Tito había conseguido trabajo como enfermero y, así, aseguraba seguir el mismo camino andado por sus dos hermanos mayores: después de egresar como técnico en enfermería, obtener trabajo en Tuxtla para costear los estudios a nivel licenciatura. El reacomodo de la historia personal hecha en la iniciación conventual, permite encontrar relación entre la vocación religiosa de Tito y el asesinato de su hermana y responder a aspectos personales y familiares: justifica el rechazo del puesto en el Hospital, disculpa su ausencia de la casa familiar en un momento de quiebre emocional, y, lo primordial, encuentra sentido a la muerte de su hermana.

En la generación que pude acompañar, todos confirmaron su vocación mediante este proceso de significación de su pasado. Todos pidieron emitir los votos religiosos y fueron aceptados. Ciertamente, la experiencia observada en estos sujetos también refleja un cambio estructural en la vocación. A pesar de pasar este proceso, no están seguros de continuar en la orden. La adhesión institucional ya no garantiza la permanencia. De ahí que hagan renovaciones anuales de los votos temporales, antes de pedir a sus autoridades emitir los votos perpetuos o solemnes. La incertidumbre vocacional después del noviciado que persiste en la vida consagrada contemporánea, es una consecuencia 
a nivel de la subjetividad del avance del proceso de secularización iniciado con la modernidad. Las precauciones institucionales residen en la extensión de la probación durante los años de "votos simples" emitidos después del noviciado. Durante este tiempo el vínculo con la congregación dependerá, en gran medida, de los vaivenes de la subjetividad de los religiosos. Es común que los frailes de mayor edad, en tono de reproche, comenten que el mal más importante de las nuevas generaciones es la indecisión.

La pertenencia a la institución católica mediante la profesión de votos no impide la flexibilidad que genera la personalización de la creencia, acorde a las condiciones actuales de lo religioso. La persistencia de la incertidumbre vocacional está fundada en la individualización de la experiencia religiosa. Ser fiel a la verdad del yo ausenta el compromiso permanente porque, como comentó varias veces un novicio, ser franciscano está más en la vivencia interior que en las expresiones exteriores tradicionales. Ni siquiera aquellos frailes que han hecho votos perpetuos o han recibo la ordenación sacerdotal están exentos de la soberanía del yo de la individualización religiosa (Beck, 2017). ${ }^{13}$ A la par de las transformaciones subjetivas de la historia personal que genera la iniciación conventual, asoma como telón de fondo de tal experiencia, la constante duda vocacional por parte de los novicios. Es así que, a pesar de haber hecho votos, la inquietud por saber si están siendo consecuentes con lo que consideran auténtico de sí mismos, hizo que experimentaran crisis e indecisiones durante todo el proceso de noviciado. ${ }^{14}$

${ }^{13}$ Las experiencias cada vez más comunes de abandono de congregaciones de sujetos con varios años como consagrados, confirma la relación de los marcos modernos de la religión y la subjetividad del creyente. Para el caso del mundo monástico, Merton (1982, p. 60), quien fuera una de las voces interreligiosas más serias del catolicismo del siglo pasado, consideraba que el incremento de las crisis vocacionales de monjes profesos estaba ocasionándose en razón de que la "autenticad que desea sinceramente y con razón el monje moderno, lo tenga o no consiente, es antes que nada una fidelidad a su propia verdad y a su propio ser interior en cuanto persona" (subrayado mío).

${ }^{14}$ Un integrante de esta generación, después de dos años como franciscano, abandonó la orden en 2018 y se integró a los estudios profesionales que había suspendido.

Debates do NER, Porto Alegre, ano 20, N. 37, P. I69-200, JAn./Jul. 2020 


\section{REFLEXIONES FINALES}

A partir de este caso de estudio he presentado una manera de pensar una orden religiosa de tal manera que se articule religión (institución) y religiosidad (prácticas rituales somáticas y narrativas de consagración). Para esto, se ha puesto en relación la tradición misionera del franciscanismo y la forma en que se ha reinterpretado en las últimas décadas para dar paso a una nueva entidad administrativa en el sureste mexicano. Por otro lado, estos elementos simbólicos que componen los cauces institucionales del franciscanismo del sureste representan el contexto para dar sentido a los procesos biográficos de quienes han decidido ingresar a esta orden religiosa. En este sentido, a la par de los estudios que privilegian una perspectiva meramente institucional sobre los religiosos o el clero, conviene observar los modos en que se actualizan a partir de experiencias de prácticas concretas.

Por otro lado, los proyectos pastorales y las posturas políticas que estos frailes estarán por construir necesitan ser observados con este elemento simbólico de la resocialización que opera en la creencia religiosa. Es decir, a la par de reproducir la institución como organización corporativa, es oportuno considerar este trasfondo subjetivo aprendido a lo largo de la formación, mediante la administración de la subjetividad en la rutina litúrgica. Esto puede ayudar a explicar fenómenos más allá del claustro, como la presencia de la religión en los procesos de organización social de corte liberacionista. Estos acontecimientos están poco estudiados desde el problema de la subjetivación y reconfiguración de los esquemas de sentido. Por ejemplo, la historia y sociología de los movimientos sociales de corte cristiano en Chiapas y América Latina carecen de indagaciones que demuestren la relación entre las organizaciones sociales y los procesos de subjetivación que conllevan a transformaciones personales y colectivas de corte religiosa. Para el caso de Chiapas es común en la literatura que se caracterice el tipo de influencia ideológica en la organización política de poblaciones campesinas e indígenas; sin embargo, poco o nada se habla de los mecanismos de 
incorporación subjetiva que modifican esquemas de sentido y posibilita tal o cual postura política.

\section{REFERENCIAS}

BECK, Ulrich. El Dios personal: la individualización de la religión y el "espíritu” del cosmopolitismo. Barcelona: Paidós, 2017.

BLANCARTE, Roberto. Historia de la Iglesia católica en México, 1929-1982.

Ciudad de México: Fondo de Cultura Económica, 2014.

CHAUVET, Fidel de Jesús. Los franciscanos en México (1523-1980). Ciudad de México: Editorial Tradición, 1989.

CRISPÍN, María Luisa. Huellas de un caminar: Misión jesuita de Bachajón. Ciudad de México: Universidad Iberoamericana, 2010.

CSORDAS, Thomas. Embodiment as a paradigm for anthropology. Ethos, United States, v. 18, n. 1, p. 5-47, 1990.

CSORDAS, Thomas. Introduction: the body as representation and being-in-the-world. In: CSORDAS, Thomas (ed.). Embodiment and experience: the existential ground of culture and self. Cambridge: Cambridge University Press, 1994. p. 1-24.

CSORDAS, Thomas. Modos somáticos de atención. In: CITRO, Silvia (coord.). Cuerpos plurales: antropología de y desde los cuerpos. Buenos Aires: Biblos, 2011. p. 83-104.

DE LA TORRE, Renée. La Ecclesia Nostra: el catolicismo desde la perspectiva de los laicos - el caso de Guadalajara. Ciudad de México: Fondo de Cultura Económica, 2006.

ECO, Umberto. El nombre de la rosa. Ciudad de México: Lumen, 1999.

ELIADE, Mircea. Muerte e iniciaciones misticas. La Plata: Terramar, 2008. 
FALCÓ PLIEGO, Luis Fernando. Malestares de afiliación: procesos de construcción de identidad en la vida religiosa y sacerdotal en México hoy. 2004. Tesis (Maestría en Ciencias Sociales) - Facultad Latinoamericana de Ciencias Sociales, Ciudad de México, 2004.

FASSIN, Didier. La fuerza del orden: una etnografía del accionar policial en las periferias urbanas. Buenos Aires: Siglo XXI, 2016.

FOUCAULT, Michel. Vigilar y castigar: nacimiento de la prisión. Ciudad de México: Siglo XXI, 2010.

GARCÍA, Antonio. Marco Polo y la Cruzada: historia de la literatura de viajes a las Indias en el siglo XIV. Madrid: Marcial Pons, 2009.

GARCÍA, Clara; RUBIAL, Antonio. Iglesia y religión: la Nueva España. Ciudad de México: Fondo de Cultura Económica, 2018.

GARCÍA, Marta Eugenia; ROSAS, Sergio Francisco. La Iglesia católica en México desde sus historiadores (1960-2010). Anuario de Historia de la Iglesia, España, v. 25, p. 91-161, 2016.

GEERTZ, Clifford. La interpretación de las culturas. Barcelona: Gedisa, 2003. GOFFMAN, Erving. Internados: ensayos sobre la situación social de los enfermos mentales. Buenos Aires: Amorrortu, 1972.

HERVIEU-LÉGER, Danièle. Le temps des moines: clôture et hospitalité. Paris: Presses Universitaires de France, 2017.

JEWDOKIMOW, Marcin. A monastery in a sociological perspective: seeking for a new approach. Warszawa: Uniwersytecie Kardynała Stefana Wyszyńskiego, 2018.

JONVEAUX, Isabelle. Asceticism: an endangered value? Mutations of asceticism in contemporary monasticism. Scripta Instituti Donneriani Aboensis, Finland, v. 23, p. 186-196, 2011. 
JONVEAUX, Isabelle. Asceticism and the place of the body in the modern monastic prayer. In: GIORDAN, Giussepe; PACE, Enzo (ed.). Mapping religion and spirituality in a postsecular world. Boston: Brill, 2012. p. 151-166. JONVEAUX, Isabelle; PALMISANO, Stefania; PACE, Enzo (ed.). Sociology and monasticism: between innovation and tradition. Boston: Brill, 2014.

KHONINEVA, Ekaterina. "Vocation in the flesh": gender and embodiment in the religious anthropology of modern Catholicism. State, Religion and Church, Moscow, v. 6, n. 2, p. 28-47, 2019.

LA BIBLIA Latinoamericana. Ciudad de México: San Pablo, 1972.

LAVRIN, Asunción. El umbral de la vida religiosa: el noviciado de los frailes mendicantes. In: LÓPEZ-CANO, María del Pilar Martínez (coord.). De la historia económica a la historia social y cultural: homenaje a Gisela Von Wobeser. Ciudad de México: Universidad Nacional Autónoma de México, 2015. p. 235-262.

LEACH, Edmund. Political systems of Highland Burma: a study of Kachin social structure. Boston: Beacon Press, 1954.

LESTER, Rebecca. The immediacy of eternity: time and transformation in a Roman Catholic convent. Religion, United Kingdom, v. 33, n. 3, p. 201-219, 2003.

LISBONA, Miguel. Sacrificio y castigo entre los zoques de Chiapas: cargos, intercambios y enredos étnicos en Tapilula. Ciudad de México: Universidad Nacional Autónoma de México, 2004.

LITURGIA de las horas. Ciudad de México: Buena Prensa, 2014. Tomo II. LONGEAT, Jean-Pierre. Veinticuatro horas de la vida de un monje. Barcelona: Kairós, 2008.

LÖWY, Michael. Guerra de dioses: religión y política en América Latina. Ciudad de México: Siglo XXI, 1999. 
LUDUEÑA, Gustavo. Dos experiencias místicas de lo numinoso. Numen: Revista de Estudos e Pesquisa da Religiáo, Juiz de Fora, v. 4, n. 1, p. 87-118, 2008.

LUDUEÑA, Gustavo. Praesentias: ascetismo y liminalidad en comunidades contemplativas benedictinas del Mercosur. Ciências Sociais e Religiäo, Campinas, v. 5, n. 5, p. 123-152, 2003.

MANZANO-MUGÍA, María. No sólo por el llamado de Dios se es monja. 1995. Tesis (Licenciatura en Antropología Cultural) - Universidad de las Américas Puebla, San Andrés Cholula, 1995.

MASFERRER, Elio. ¿Es del César o es de Dios? Un modelo antropológico del campo religioso. Ciudad de México: Plaza y Valdés: UNAM, 2004.

MASFERRER, Elio. Los ritos de paso y su incidencia en el campo religioso mexicano. Cuicuilco, Ciudad de México, v. 20, n. 57, p. 191-205, 2013.

MELLA, Pablo. "Esto no es una pipa": mística y estudios de la religión en América Latina - una perspectiva liberadora. In: ALONSO, Aurelio (comp.). América Latina y el Caribe: territorios religiosos y desafíos para el diálogo. Buenos Aires: Consejo Latinoamericano de Ciencias Sociales, 2008. p. 365-395.

MERTON, Thomas. Acción y contemplación. Barcelona: Kairós, 1982.

MEYER, Jean. La Iglesia católica en México 1929-1965. Ciudad de México: Centro de Investigación y Docencia Económicas, 2005.

MORALES, Francisco. México independiente y franciscanos. In: MORALES, Francisco (ed.). Franciscanos en América: quinientos años de presencia evangelizadora. Ciudad de México: Conferencia Franciscana de Santa María de Guadalupe, 1993. p. 537-552.

PADILLA, Mario. Gráficas y relatos: cómo evolucionaron las vocaciones sacerdotales en la Arquidiócesis de México, 1930-2000. Relaciones, México, v. 36, n. 141, p. 221-257, 2015. 
PADILLA, Mario. Vocación y reclutamiento sacerdotal en la Arquidiócesis de México. 2008. Tesis (Doctorado en Ciencias Sociales) - El Colegio de México, Ciudad de México, 2008.

PATIÑO, María. Religiosas católicas en la ciudad de Aguascalientes: una mirada sociocultural de los relatos de vida. Aguascalientes: Universidad Autónoma de Aguascalientes, 2017.

RAPPAPORT, Roy. Ritual y religión en la formación de la humanidad. Madrid: Cambridge University Press, 2001.

RICHI, Gabriel. La vida consagrada: nota bibliográfica. Carthaginensia, Murcia, v. 34, n. 65, p. 115-136, 2018.

ROBLEDO, Gabriela. Los dominicos y la construcción de una iglesia maya en Chiapas y Guatemala. Revista Latinoamericana de Investigación Crítica, Buenos Aires, año III, n. 5, p. 59-78, 2016.

RUBIAL, Antonio. La hermana pobreza. El franciscanismo: de la Edad Media a la evangelización novohispana. Ciudad de México: Universidad Nacional Autónoma de México, 1996.

RUBIAL, Antonio (coord.). La Iglesia en el México colonial. Ciudad de México: Universidad Nacional Autónoma de México, 2013.

SBARDELLA, Francesca. Inhabited silence: sound constructions of monastic spatiality. Etnográfica, Lisboa, v. 17, n. 3, p. 515-534, 2013.

SIMMEL, Georg. La religión. Barcelona: Gedisa, 2013.

TAHAR, Malik. La Compañía de Jesús y la teología de la liberación: convergencias y divisiones sociopolíticas del catolicismo contemporáneo en América Latina. Historia y Grafia, Ciudad de México, n. 29, p. 95-129, 2007.

TURNER, Victor. Dramas, fields, and metaphors. London: Cornell University Press, 1974.

TURNER, Victor. El proceso ritual. Madrid: Taurus, 1988. 
VAN GENNEP, Arnold. Los ritos de paso. Madrid: Alianza, 2008.

VIQUEIRA, Juan Pedro. Éxitos y fracasos de la evangelización en Chiapas (1545-1859). In: SIGAUT, Nelly (ed.). La Iglesia católica en México. México: El Colegio de Michoacán, 1997. p. 69-98.

WACQUANT, Loïc. Entre las cuerdas: cuadernos de un aprendiz de boxeador. Buenos Aires: Siglo XXI, 2006.

Recebido em: 10/12/2019 Aprovado em: 04/08/2020 